\title{
Findings From a Quantitative Approach of Nurses Possibly Related to the Nursing Shortage Before Policy Modification in Macao
}

\author{
Cindy Sin U Leong*, Ken Gu, Ming Liu \\ School of Health Science, Macao Polytechnic Institute, Macao
}

\begin{abstract}
The purpose of the present survey was to determine agreement levels among Macao nurses in the public sector on 57 items that could be related to the nursing shortage in Macao. An earlier qualitative inquiry showed that nurses working in the public health sector there had strong concerns about the number of nursing staff. Such a situation might decrease the likelihood of delivering quality care. A quantitative approach was used to assess the degree to which nurses agreed with the 57 items. These questionnaires were sent to each ward in the public hospital and a mental hospital, to six health care centers, and to two health stations affiliated with Taipa health care centre. Of 743 questionnaires distributed, 467 were returned $(62.85 \%)$. Categories in which there was a preponderance of high levels of agreement were salary and employment benefits, performing non-nursing duties and tasks that require basic skills, continuing nursing education, and patient population. Nurse Managers should have promptly actions to reform those nurses views previously in order to show that frontline nursing staff are supported.
\end{abstract}

Keywords Nurse Staff, Job Satisfaction, Human Resource Management

\section{Introduction}

The public health care system of Macao Special Administrative Region (Macao), which is comprised of an acute hospital complex, a mental hospital, six health care centers, and two health stations, provides both specialized and primary health care as well as disease prevention and health promotion services in Macao Peninsula, Taipa, and the Coloane Islands[1] Macao Special Administrative Region lies along the South China Sea and comes under the aegis of the People's Republic of China while, for the most part, functioning as an independent entity.

Primary health care services, which are scattered throughout the community, are free to the residents of Macao. Normally, Macao residents will seek medical services in the nearest health centre; those who require specialized treatment are referred to an outpatient clinic within an acute hospital for further follow-up. At the public acute hospital, service is free for adults aged 65 years or older, patients with cancer or infectious diseases, those with mental or psychological problems, and those who have a relatively low family income. This hospital also provides free service for maternity care and from birth through grade 12 when-

* Corresponding author:

suleong@ipm.edu.mo (Cindy Sin U Leong)

Published online at http://journal.sapub.org/nursing

Copyright (C) 2012 Scientific \& Academic Publishing. All Rights Reserved ever young people are required to be admitted there. The hospital, which has 476 beds, provides 22 services, including all kinds of medical and surgical treatment, emergency units, intensive care units, a burn unit, surgical units (operating units), units for physical medicine and rehabilitation, oncology, maternity, pediatric and orthopedics for pediatric and adults, hemodialysis, and outpatient consultation in a variety of specialties. Given the population of Macao and the fact that it has only one hospital complex, it is not surprising that more than 400,000 patients are seen annually at this hospital.

The mental hospital, which provides services for patients whom have psychological or mental problems from teenagers to older adults, has 60 beds. This hospital is located in Taipa Island and there were 32 nurses care the in-patients. The out-patient clinic is located in the acute hospital complex.

Considering the advantages of easy access and treatment without charge, most of the residents of Macao, especially the older adults, prefer to seek free care at the health care centers or in the acute hospital. The population has an average life expectancy of 80.7 years, and $7.7 \%$ of the population is aged 65 years or older. Not surprisingly, demand for public health services in Macao is not well matched with supply. The workload for Macao nurses is increasing and has already reached a level at which many nurses indicate dissatisfaction with their work. Because of the shortage of nursing resources, it was considered urgent to conduct a 
survey among Macao nurses to elicit their feelings in a variety of areas; this survey was based on a previous study that used a qualitative approach. The earlier study had identified concerns about workload and dissatisfaction among the nurses; for the present study, we created 7 categories and grouped these items under one theme. Under the theme, problems that concerned the staff, the categories we finalized were workload, turnover, salary and employment benefits, nursing staff, performing non-nursing duties and tasks that require low/basic care skills, continuing nursing education, and the patient population.

The aim of the present study was to investigate whether the 7 categories identified had an effect on the nursing shortage within the public health care system in Macao by asking nurses working within that system to express their levels of agreement/disagreement with a variety of statements arranged under these 7 categories.

\section{Methods}

\subsection{Design and participants}

The survey, which had a descriptive design, was conducted among all the nurses who worked in the one public hospital, the one mental hospital, or the six health care centres (one in each of the SAR's six geographical regions) and two health stations in Macao.

\subsection{Instrument}

Ten experienced nurse specialists (nine female and one male), all of whom had administered practicum, were invited to provide their expertise to the process of validating the questionnaire, which drew on the previous qualitative study. These nurses were from a critical care, surgical, or medical unit in the public hospital or from a health care centre. They graded each item with score ranged from 1.0 to 4.0 points. A content validity index (CVI) with an average score of 0.78 for those items that rated above 3.0 points were left for calculation. That meant those items rated 1.0 or 2.0 points were not used for CVI calculation.

On the first round of the content validity test, the maximum CVI for any one category was 0.94 ; the minimum, 0.49 ; and the mean, 0.68. After all of the comments and scores from the 10 nurse specialists were considered, the original 134 items were reduced to 89 , with many of these items reformulated. The test-retest reliability/internal consistency of the survey categories was assessed by having four reviewers (not from the original group of 10 nurse specialists) express a level of agreement (ranging from $1=$ strongly agree to $5=$ strongly disagree) with each of the items within the categories (three of the reviewers were front-line nurses at the acute hospital [surgical, medical, and critical wards], and the other was a front-line nurse at a health care center). For the 7 categories the Cronbach's alpha ranged from 0.77 to 0.94 . The items were adjusted and reduced to 57 under the direction of the panel of 10 experts. Participants in the survey were given the same 5-point scale used by the four reviewers to measure their agreement, i.e., a scale ranging from $1=$ strongly agree to $5=$ strongly disagree.

\subsection{Procedure}

This research study was approved by the Macao Polytechnic Institute Research Committee Board as well as the research assessment team of the acute hospital complex. All participants were given a package consisting of a detailed outline of the study, a consent form, and the questionnaire (Chinese version). Data was collected during an 8-week period in June-July 2009. The required amounts of packages were delivered to the two public hospitals (one general and the other a mental hospital) and the six health care centers (two health stations). At the same time, two boxes were distributed to these eight institutions, one for collecting envelopes with the consent form and the second for collecting envelopes that contained the questionnaire. Because all of the nurses working in the acute hospital, the mental hospital, and the six health care centres were included, the survey involved nurses from surgical, medical, and critical care wards, outpatient clinics, the health care centres, and health stations that were affiliated with the health centres.

Table 1. Demographic Data for the Sample $(N=467)$

\begin{tabular}{cccc}
\hline & Characteristic & $\mathrm{N}$ & $\%^{*}$ \\
\hline \multirow{2}{*}{ Gender } & Female & 434 & 92.9 \\
& Male & 33 & 7.1 \\
\hline \multirow{4}{*}{ Marital Status } & Married & 286 & 61.6 \\
& Divorced & 14 & 3.0 \\
& Separated & 3 & 0.6 \\
& Cohabitating & 3 & 0.6 \\
Taken Courses & Single & 153 & 33.0 \\
Recently & Other & 5 & 1.1 \\
\hline \multirow{3}{*}{ Highest Level of } & Yes & 261 & 55.9 \\
Education & No & 206 & 44.1 \\
& PhD & 1 & 0.2 \\
& Master's degree & 12 & 2.6 \\
& Specialist program + & 27 & 5.8 \\
& Associate's degree & 305 & 65.6 \\
& Higher diploma++ & 37 & 8.0 \\
& Secondary school diploma & 81 & 17.4 \\
No. of Working & $<3$ & 2 & 0.4 \\
Years & 3 to $<5$ & 65 & 13.9 \\
& 5 to $<10$ & 48 & 10.3 \\
Age (Years) & 10 to $<20$ & 88 & 18.8 \\
& $>20$ & 147 & 31.4 \\
& $<25$ & 118 & 25.3 \\
\hline & $25-34$ & 44 & 9.4 \\
& $35-44$ & 149 & 31.9 \\
& $45-54$ & 123 & 26.3 \\
& $55-64$ & 79 & 16.9 \\
& & 14 & 3.0 \\
\hline
\end{tabular}

* Percentages that do not add to $100.0 \%$ indicate missing data (or rounding error). + A specialist program is a two years program providing for experienced nurses whom should have bachelor degree.

++ A higher diploma signifies a nurse with three years of hospital-based training.

\subsection{Results}

The first part of the survey elicited demographic information, and the second part contained the 57 items. Of the 743 questionnaires, $467(62.85 \%)$ were returned. The great majority of respondents were female $(92.9 \%)$, and almost one-third (31.9\%) were aged 25 to 34 years (Table 1). All participants were full-time, and the majority $(61.6 \%)$ were married. Of the 467 nurses, 261 (55.9\%) had taken courses 
recently. By far the most common level of educational attainment was the bachelor's degree $(65.6 \%)$, with the number below that level exceeding the number above. Of five possible amounts of experience, the most common was 10 to 20 years $(31.4 \%)$.

To simplify review of the findings, "strongly agree" $(1$ on the scale of 1 to 5 ) and "agree" ( 2 on that scale) were grouped in one column, and "strongly disagree" (5 on the scale) and "disagree" (4) were combined in another column (Table 2).

Under the first category (workload) under the theme, problems that concerned the staff, the only item for which less than $63 \%$ of the nurses either "agreed" or "strongly agreed" (hereafter, "agreed" or "agreement") was "ratio of 1 nurse to 15 patients during night shift" (51.6\%). Five items ("heavy workload causes nurses to be frustrated," "hardly understood by outsiders," "fixed ratio of nurses and patients," "feel exhausted after work," and "frequently have to obtain new knowledge and learn new techniques") achieved greater than $90 \%$ agreement.

In the second category (turnover), the three items (out of eight) that achieved greater than $90 \%$ agreement was "increased demand in community," "front-line nurse is insufficient," and "inadequate number of nurses increases the risk of making errors." In the third category (salary and employment benefits), agreement was over $90 \%$ for six of the eight items and $89.3 \%$ for a seventh. The remaining item, "salary does not reflect my seniority," drew only $73.0 \%$ agreement. In category no. 4 (nursing staff), one item, "no sense of belonging for newly recruited nurses," had an agreement level of $95.0 \%$, and two other items had levels of above $85 \%$ ("great responsibilities and pressure for inexperienced new nurses" and "management does not understand nurses' heavy workload"), but for three items, agreement was below $65 \%$ ("inadequate guidance for new staff," "management neglects newly recruited staff's concerns and needs," and "senior nurses too busy to mentor new staff"). For the remaining three categories (perform non-nursing duties and tasks that require low/basic skills, continuing nursing education, and patient population), agreement levels were generally very high, exceeding $90 \%$ for all but one item in each of the three categories was out of that percentage.

\section{Discussion}

The findings from this quantitative study of Macao nurses working in the public sector shed considerable light on their attitudes relative to issues that may be tied to the nursing shortage in that territory. In particular, items where there was a high level of agreement among the nurses should be considered by those addressing the nursing shortage in Macao or, indeed, in other areas within the developed world. To make more effective use of the findings it may be profitable, as well, to make comparisons between findings from the Macao study and reports from other areas.

\subsection{Demographic Data}

In this study, $41 \%$ of responding nurses were aged 35-39 or below. In contrast, in western countries like Australia, the USA, and Britain, the average age of nurses was found to be over 40, and Australia was found to have an aging nurse population[2-5] In Macao the average age is similar to that in mainland China, which might in fact have a somewhat younger average age than Macao[6] Versus to western countries, the proportion of nurses in Macao who were men was much lower, but the proportion of nurses who were married was higher $(61.6 \%)[2-5]$ The percentage of those with a bachelor's degree in Macao was quite high $(65.6 \%$ in our survey had at least a bachelor's degree, while $2.6 \%$ had a master's and $0.2 \%$ a doctorate); in comparison, percentages with a bachelor's degree were found to be much lower in the USA (35\%) and dramatically lower in mainland China (2-3. $42 \%)[6-7]$

\subsection{Workload}

Although only five of the 18 items under the category "workload" elicited agreement levels of $90 \%$ or higher, this was the only category with more than nine items, and thus it is worth exploring in greater detail. A high workload for nurses could definitely lead to mental frustration and physical exhaustion, and our survey supports that conclusion. A content analysis, performed in California, USA[8], lends support to our findings. Other researchers have found that a high workload would decrease job satisfaction because of stress and burnout after shifts are finished[9-12] The item "fixed ratio of nurses and patients" elicited a very high level of agreement in our study (95.9\%), suggesting that the ratio should be adjusted by the kinds of patients and their specific care. According to the report[6], the ratio of nurses to patients on the day shift (7:00 am to 7:00 pm) in surgical wards in both the U.S. and China was 1 nurse to 3-4 patients.

Both the state of California, USA[13], and the state of Victoria, Australia[14] require a minimum nurse-patient ratio. In addition, California state described a legal requirement in acute hospital for general surgical and medical units of one nurse per five patients[13]. In contrast, Victoria, Australia[14] reported a mandatory minimum ratio of 1:4.

In Macao, however, in the surgical and medical wards of the public acute-care hospital the nurse-patient ratio was 1:6-7 from 8:00 am to $4: 00 \mathrm{pm}$ and $1: 9$ from $4: 00 \mathrm{pm}$ to 12:00 midnight (the afternoon shift). During the night shift (midnight to 8:00 am) the ratio was 1:14. In most cases the surgeries were performed in the morning; when the operation was finished the patients would be admitted to the surgical ward on the afternoon shift. If the patient's condition was unstable and he/she needed complex treatment and perhaps a special transfusion after being admitted to the surgical ward, two primary nurses (responsible between them for 28 beds) and one functional nurse (who assisted in all duties except the patients' documentation) were assigned to manage this high workload; this was hardly enough staffing. Furthermore, the functional nurse would leave the ward by $10 \mathrm{pm}$, not midnight in some wards. 
Table 2. Response on nursing manpower resources survey $(N=467)$

\begin{tabular}{|c|c|c|c|c|c|c|c|}
\hline \multirow[t]{2}{*}{ Concepts } & \multicolumn{2}{|c|}{$\begin{array}{c}\text { Strongly } \\
\text { Agree/Agree } \\
\end{array}$} & \multicolumn{2}{|c|}{ Uncertain } & \multicolumn{2}{|c|}{$\begin{array}{c}\text { Strongly Disag- } \\
\text { ree/Disagree }\end{array}$} & \multirow[t]{2}{*}{$M(S D)$} \\
\hline & $\mathbf{N}$ & $\%$ & $\mathbf{N}$ & $\%$ & $\mathbf{N}$ & $\%$ & \\
\hline \multirow{2}{*}{\multicolumn{8}{|c|}{$\begin{array}{l}\text { Problems that concerned the staff } \\
\text { Workload }\end{array}$}} \\
\hline & & & & & & & \\
\hline Inadequate nurses for substitution & 294 & 63.3 & 71 & 15.3 & 100 & 21.5 & $2.4(0.82)$ \\
\hline Twice the workload in emergency conditions & 394 & 84.7 & 51 & 11.0 & 20 & 4.3 & $2.8(0.49)$ \\
\hline Rapid turnover of patients & 393 & 84.9 & 62 & 13.4 & 8 & 1.7 & $2.8(0.42)$ \\
\hline Responsible for all duties & 391 & 84.4 & 37 & 8.0 & 35 & 7.6 & $2.8(0.57)$ \\
\hline Heavy workload causes illness of staff & 406 & 87.1 & 46 & 9.9 & 14 & 3.0 & $2.8(0.44)$ \\
\hline Ratio of 1 nurse to 15 patients during night shift & 239 & 51.6 & 146 & 31.5 & 78 & 16.8 & $2.3(0.75)$ \\
\hline Increase no. of doctors and improve setup of clinic department & 402 & 86.5 & 47 & 10.1 & 16 & 3.4 & $2.8(0.46)$ \\
\hline Heavy workload causes nurses to be frustrated & 435 & 94.0 & 21 & 4.5 & 7 & 1.5 & $2.9(0.32)$ \\
\hline Nonstop working every day & 407 & 88.1 & 52 & 11.3 & 3 & 0.6 & $2.9(0.35)$ \\
\hline Hardly understood by outsiders & 441 & 94.8 & 19 & 4.1 & 5 & 1.1 & $2.9(0.28)$ \\
\hline No fixed ratio of nurses and patients & 446 & 95.9 & 15 & 3.2 & 4 & 0.9 & $2.9(0.25)$ \\
\hline Working pressure & 364 & 78.3 & 53 & 11.4 & 48 & 10.3 & $2.7(0.65)$ \\
\hline Feel exhausted after work & 427 & 91.8 & 23 & 4.9 & 15 & 3.2 & $2.9(0.41)$ \\
\hline Work is laborious & 378 & 81.1 & 70 & 15.0 & 18 & 3.9 & $2.8(0.50)$ \\
\hline Doctors' working hours extended & 377 & 80.9 & 72 & 15.5 & 17 & 3.6 & $2.8(0.50)$ \\
\hline Senior nurses working at night & 408 & 87.7 & 40 & 8.6 & 17 & 3.7 & $2.8(0.46)$ \\
\hline Often have to obtain new knowledge and learn new techniques & 450 & 96.8 & 13 & 2.8 & 2 & 0.4 & $3.0(0.21)$ \\
\hline Feel heavy workload & 308 & 66.7 & 118 & 25.5 & 36 & 7.8 & $2.6(0.63)$ \\
\hline \multicolumn{8}{|l|}{ Turnover } \\
\hline High turnover rate & 288 & 62.1 & 134 & 28.9 & 42 & 9.1 & $2.5(0.66)$ \\
\hline Increased demand in community & 420 & 90.3 & 37 & 8.0 & 8 & 1.7 & $2.9(0.37)$ \\
\hline Competition between government and private hospitals & 341 & 73.5 & 92 & 19.8 & 31 & 6.7 & $2.7(0.60)$ \\
\hline Front-line nurse is insufficient & 448 & 96.1 & 14 & 3.0 & 4 & 0.9 & $3.0(0.25)$ \\
\hline Loss of newly recruited nurses & 395 & 84.8 & 48 & 10.3 & 23 & 4.9 & $2.8(0.51)$ \\
\hline Inadequate number of nurses increases the risk of making errors & 437 & 94.0 & 23 & 4.9 & 5 & 1.1 & $2.9(0.30)$ \\
\hline Prefer to work in comfortable environment & 262 & 56.5 & 128 & 27.6 & 74 & 15.9 & $2.4(0.75)$ \\
\hline Private clinic or centers offer attractive remuneration & 341 & 73.5 & 92 & 19.8 & 31 & 6.7 & $2.6(0.66)$ \\
\hline \multicolumn{8}{|l|}{ Salary and employment benefits } \\
\hline Salary does not reflect my seniority & 340 & 73.0 & 95 & 20.4 & 31 & 6.7 & $2.7(0.60)$ \\
\hline Salary and benefits should be increased & 450 & 96.6 & 13 & 2.8 & 3 & 0.6 & $3.0(0.23)$ \\
\hline Salary and benefits do not keep up with inflation & 433 & 92.9 & 27 & 5.8 & 6 & 1.3 & $2.9(0.32)$ \\
\hline Provide extra time and financial incentives for nurses on training & 448 & 96.1 & 15 & 3.2 & 3 & 0.6 & $3.0(0.24)$ \\
\hline Salary does not reflect educational qualifications & 416 & 89.3 & 40 & 8.6 & 10 & 2.1 & $2.9(0.39)$ \\
\hline Salary does not reflect great responsibilities and pressure & 425 & 91.2 & 32 & 6.9 & 9 & 1.9 & $2.9(0.37)$ \\
\hline Allocate more resources to the wages and benefits of the nurse & 449 & 96.4 & 14 & 3.0 & 3 & 0.6 & $3.0(0.23)$ \\
\hline Introduce new law to replace unreasonable old law & 436 & 94.8 & 21 & 4.6 & 3 & 0.7 & $3.0(0.26)$ \\
\hline \multicolumn{8}{|l|}{ Nursing staff } \\
\hline Great responsibilities and pressure for inexperienced new nurses & 407 & 87.7 & 53 & 11.4 & 4 & 0.9 & $2.9(0.36)$ \\
\hline Inadequate guidance for new staff & 297 & 64.1 & 127 & 27.4 & 39 & 8.4 & $2.6(0.65)$ \\
\hline Management neglects newly recruited staff's concerns and needs & 240 & 52.1 & 171 & 37.1 & 50 & 10.8 & $2.4(0.68)$ \\
\hline Senior nurses too busy to mentor new staff & 258 & 55.8 & 150 & 32.5 & 54 & 11.7 & $2.4(0.69)$ \\
\hline Inexperienced new staff not ready to care for critical patients & 378 & 81.6 & 59 & 12.7 & 26 & 5.6 & $2.8(0.54)$ \\
\hline Management does not understand nurses' heavy workload & 396 & 85.7 & 54 & 11.7 & 12 & 2.6 & $2.8(0.44)$ \\
\hline No sense of belonging for newly recruited nurses & 439 & 95.0 & 22 & 4.8 & 1 & 0.2 & $2.9(0.23)$ \\
\hline \multicolumn{8}{|l|}{ Perform non-nursing duties and tasks that require basic skills } \\
\hline Handling patients' complaints and managing chores & 427 & 92.4 & 22 & 4.8 & 13 & 2.8 & $2.9(0.39)$ \\
\hline Shift low levels of basic care to medical assistants & 436 & 94.0 & 19 & 4.1 & 9 & 1.9 & $2.9(0.34)$ \\
\hline No clear guidelines on the duties for medical assistant & 373 & 80.4 & 59 & 12.7 & 32 & 6.9 & $2.7(0.58)$ \\
\hline Prefer to pay more attention to health care and education & 430 & 92.9 & 25 & 5.4 & 8 & 1.7 & $2.9(0.34)$ \\
\hline Provide more training to medical assistants to assist nurse & 448 & 97.0 & 12 & 2.6 & 2 & 0.4 & $3.0(0.21)$ \\
\hline Should have medical assistants with basic skills to alleviate nurse' workload & 443 & 95.7 & 16 & 3.5 & 4 & 0.9 & $2.9(0.26)$ \\
\hline \multicolumn{8}{|l|}{ Continuing nursing education } \\
\hline Need to obtain new knowledge and learn new technologies & 436 & 94.0 & 26 & 5.6 & 2 & 0.4 & $2.9(0.26)$ \\
\hline Provide additional time and allowances for nurses to take absences for study & 449 & 97.0 & 14 & 3.0 & 0 & 0 & $3.0(0.17)$ \\
\hline No opportunities for promotion even with increased qualifications & 446 & 96.3 & 15 & 3.2 & 2 & 0.4 & $3.0(0.22)$ \\
\hline Lack clear guidelines for continuing education & 410 & 88.6 & 42 & 9.1 & 11 & 2.4 & $2.9(0.41)$ \\
\hline Should be lifelong commitment to learning & 437 & 94.4 & 23 & 5.0 & 3 & 0.6 & $2.9(0.27)$ \\
\hline Increasing professional knowledge will improve quality of care & 447 & 96.8 & 15 & 3.2 & 0 & 0 & $3.0(0.18)$ \\
\hline Patient population & & & & & & & \\
\hline Increasing aging population increases the workload and pressure & 448 & 96.8 & 13 & 2.8 & 2 & 0.4 & $3.0(0.21)$ \\
\hline Public expects high nursing quality & 451 & 97.4 & 6 & 1.3 & 6 & 1.3 & $3.0(0.25)$ \\
\hline Increased levels of health insurance increase demand for health services & 409 & 88.5 & 41 & 8.9 & 12 & 2.6 & $2.9(0.42)$ \\
\hline Having a healthy city increases demand for nursing services & 440 & 95.0 & 17 & 3.7 & 6 & 1.3 & $2.9(0.29)$ \\
\hline
\end{tabular}

Thus, it is no surprise that 446 out of 465 nurses $(95.9 \%$, two did not respond to this item) in our survey expressed dissatisfaction with the fixed ratio of nurses and patients (i.e., they indicated their agreement with this item on the 
survey). Clearly, this would be far beyond what the front-line nurse might manage efficiently. For all the general surgical and medical wards in the public acute-care hospital, on holidays and weekends the nurse-patient ratio was actually worse because one less nurse worked the morning shift. This fact reinforces the apparent high level of dissatisfaction with the fixed ratio of nurses to patients. The hospital administration should consider the overall level of severity of the patients' illnesses, the higher patient turnover in today's hospitals, and the complex treatment and care that these patients require. Finally, hospital management should be aware of studies tying heavy workloads to job dissatisfaction[15-16]

Compared with Hong Kong, it appears that Macao has a better nurse-patient ratio. Recently, two Hong Kong newspapers reported that on the afternoon shift in the public hospitals the average ratio of nurses to patients was $1: 16$, contributing to overload among the nurses[17-18]; this contrasts with the 1:9 ratio in Macao during the afternoon shift. The workload was less and the nurse-patient ratio was better in private hospitals, leading nurses to move there for a better working environment. Elsewhere, in the Quangdong province in mainland China, the reasons for "losing nurses" were "stressful workload and "irregular shifts"[19]. Consequent psychological problems were seen among the nurses with signs and symptoms of hormonal changes and expressions of extreme nervousness due to their irregular schedule and the discordant relationship of nurse and patients. It was especially obvious in the emergency ward.

\subsection{Salary and Employment Benefits}

Nurses in our study had high levels of agreement with items such as "salary and benefits should be increased" (96.6\%), "salary and benefits did not keep up with inflation" $(92.9 \%)$, and "payment did not reflect their great responsibilities and pressure" (91.2\%). These findings were not unexpected. In addition, nurses were not satisfied with provisions for on-the-job training $(96.1 \%$ expressed agreement with the relevant item) and the law that had been in place for more than two decades in this area. Unlike the previous "traditional law," which gave nurses one additional month of holiday after every three years of work and also gave study leave and payment for study and training, the law in place did not include any of these provisions. Therefore, agreement was high (94.8\%) for "introduce new law to replace unreasonable current law" and "allocate more resources to the wages and benefits of the nurse" (96.4\%).

In both the United States and Canada[20-22], there have been reports that indicated similar feelings of nurses in these areas. In Hong Kong, it has been reported that the low payment of nurses in public hospitals led to $70 \%$ of the experienced nurses shifting to private hospitals, which offered higher payment and benefits[17-18] And in Quangdong, the southern-most province in mainland China, the turnover rate was up to $10 \%$ last year[19]

\subsection{Performing Non-Nursing Duties and Care that}

\section{Requires A Low Level of Skill}

Nurses in Macao have had to provide all the care to their patients, all the way from care that requires a very low level of skills to very advanced interventional care. The low-level care includes, for example, bedside bathing, changing charts, taking vital signs, helping with oral feeding, and even the ordering of materials. Advanced nursing care includes transfusion of blood/fluids, injections, management of circulation and respiration, and other special therapy according to the ward's focus. As a consequence, nurses on the morning shift were confronted with all different kinds of duties and responsibilities. In addition, there is no intravenous injection team or respiratory team in Macao, as is the case in some hospitals in the USA. There are however, some assistants in the wards who are responsible for circulating documents and for transporting samples of urine, sputum, and blood. Even with such assistants, however, the nurses too often had to perform low-level care in addition to advanced care. For example, for advanced care skill in the intensive care unit (ICU), nurses even had to perform hemodialysis in cases where the patients were in urgent need. Our study indicates that nurses in Macao preferred to shift basic care to assistant personnel ( $94.0 \%$ agreement) by providing more training to them to assist nurses $(97.0 \%$ agreement) and having medical assistants with basic skills alleviate the nurse's workload (95.7\%).

In addition, in Macao there is no unit secretary in the ward to manage the daily chores for nurses as there is in the USA. Thus, nurses in Macao are fully involved with tasks that require physical activity and often miss out on the enjoyment of psychological communication with patients such as in teaching and getting to be familiar with the patients and their family members. As shown in studies[23-24], nurses would be more satisfied with their jobs if they had interaction with patients and their family members and had more time for professional growth. Unfortunately, in Macao, the nurses did not have much chance to communicate with and teach patients and their family members.

\subsection{Continuing Nursing Education}

The issue of continuing education is of great importance to these Macao nurses. They demonstrated a high level of agreement with the idea that continuing nursing education should be a lifelong commitment $(94.4 \%)$, and they gave similarly high agreement to "need to learn new knowledge and technologies" $(94.0 \%)$. However, they wanted "additional time and allowances for nurse on study leave" (97.0\%). According to a study[25] that was conducted on 2,208 hospitals and long-term care facilities in Canada, investment in staff training decreased levels of turnover there. Alternatively, it has been reported that if nurses were not happy with having fewer chances for promotion after they had acquired additional knowledge and skills, the turnover rate was high whether in Hong Kong or in Britain[17,26]. Moreover, in recent months there have been many reports from Hong Kong related to high turnover among front-line nurses be- 
cause of a lack of promotion even though they had 10 years of experience and very good knowledge levels, education, and skills.

\section{Conclusions}

Nurses in the public sector in Macao are concerned about the level of their salaries and benefits, the need to perform non-nursing tasks that require lower levels of care, obtaining more support for continuing education, and facing the demands of the population for more care. These findings are not surprising, but still they call for concerted action on the part of health care leaders in management in Macao, especially in the public system. One year after the conclusion of the survey the salaries of the nurses were raised. However, the number of beds was increased in each ward, especially in the surgical and medical wards. Thus, the number of beds increased from 28 or 41 to 33 or 47 in each ward. No additional nurses were added on the morning shift, but one nurse was added to the afternoon and night shifts. In brief, things did not actually get better on the morning shift, and many nurses would not like to work on that shift because the morning care and dressing changes might take four or even five hours to be completed. Some nurses complained about the increase in workload enacted with the increase in salary. More research is required to recheck the situation after conditions change.

\subsection{Limitation}

Conducting this survey during the summer may not have been optimal, as many nurses may have not been present when it was distributed or may have neglected to return it because they were going on holiday. Theoretically, this could have caused some biasing of the results, but that seems unlikely to have been a serious problem because of the large number of surveys that were actually returned. The researcher in charge personally encouraged the nurses to participate, but on only one occasion at the time of distribution. Still, that should have been sufficient.

\section{ACKNOWLEDGEMENTS}

The authors would like to thank the Macao Polytechnic Institute for funding this study (RP/ESS-2/2008). The authors would also like to acknowledge all the participants conducting this survey.

\section{REFERENCES}

[1] Health Bureau (2011) Retrieved from http://www.ssm.gov.mo/design/introduction/eintroducefs.ht $\mathrm{m}$

[2] AIHW (2010) Nursing and midwifery labour force 2008. Cat. no. AUS 130. Canberra: Australia's National Agency for Health and Welfare Statistics and Information/AIHW. Retrieved from

http://www.aihw.gov.au/publication-detail/?id=6442468396

[3] Royal College of Nursing (2008) An RCN study into the challenges facing today's nursing students in HK. Retrieved from

http://www.rcn.org.uk/ data/assets/pdf file/0008/197756/0 03306.pdf

[4] Bliss M. (2005) Average age of nurses increases, Southeast Missourian, South East Health. Retrieved from http://www.semissourian.com/story/1123934.html

[5] Kendig H. (2004) The ageing of Australian society: Economic, fiscal and societal implications. Task Force Report, Future Summit Australia conference. Sydney, May 7, 2004

[6] Kalisch B.J., \& Liu Y. (2009) Comparison of nursing: China and the United States. Nursing Economics 27, 322-331

[7] Cao J., Ye W.Q., Zhang L.J., Lu X.Y., \& Sun Y. (2009) International perspectives: Clinical nursing system and staff composition in Shanghai. Journal of Nursing Administration, $3,113-114$

[8] McNeese-Smith D.K. (1999) A content analysis of staff nurse descriptions of job satisfaction and dissatisfaction. Journal of Advanced Nursing 29, 1332-1341

[9] Aiken L.H., Clarke S.P., Sloane D.M., Sochalski J., \& Silber J.H. (2002) Hospital nurse staffing and patient mortality, nurse burnout, and job dissatisfaction. Journal of the American Medical Association, 288, 1987-1993

[10] Andrews D.R., \& Dziegielewski S.F. (2005) The nurse manager: Job satisfaction, the nursing shortage and retention. Journal of Nursing Management, 13, 286-295

[11] Edwards D., Burnard P., Coyle D., Fothergill A., \& Hannigan B. (2000) Stress and burnout in community mental health nursing: A review of the literature. Journal of Psychiatric and Mental Health Nursing, 7, 7-14

[12] Stordeur S., D'hoore W., \& Vandenberghe, C. (2001) Leadership, organizational stress, and emotional exhaustion amongst hospital nursing staff. Journal of Advanced Nursing, $35,533-542$

[13] Lang T.A., Hodge M. Olson V., Romano, P.S., \& Kravitz, R.L. (2004) Nurse-patient ratios: A systematic review on the effects of nurse staffing on patient, nurse employee, and hospital outcomes. Journal of Nursing Administration, 34, 326-337

[14] Gerdtz M.F., \& Nelson S. (2007) 5-20: A model of minimum nurse-to-patient ratios in Victoria, Australia. Journal of Nursing Management, 15, 64-71

[15] Mrayyan M.T. (2005) Nurse Job satisfaction and retention: Comparing public to private hospitals in Jordan. Journal of Nursing Management, 13, 40-50

[16] Shapiro J.P. (2001) Nurses are overworked, stressed, and hard to find. US News and World Report, 130(24), 54-57

[17] Chen K.Y. \& Chen P. B. (2011, May 10) Public hospital lost $70 \%$ of experienced nurses especially in obstetrics and pediatrics units (in Chinese). Apple Daily News, p. A6 
[18] Ming Pao Special Report (2011, May 10) Legislation requested Health Bureau to submit the nursing manpower resource planning (in Chinese). Ming Pao News, p. A6

[19] Reporter in Canton (2011, May 15) Up to $10 \%$ turnover rate in nurses of Quangdong province in mainland China (in Chinese), Macao Daily New, p. B8

[20] Beu B. (2004) the nursing shortage and the Nurse Reinvestment Act. AORN Journal 79, 1061-1063

[21] Hegney D., Plank A., \& Parker V. (2006) Extrinsic and intrinsic work values: Their impact on job satisfaction in nursing. Journal of Nursing Management, 14, 271-281

[22] Spetz J., \& Adams S. (2006) How can employment-based benefits help the nurse shortage? Making nursing more attractive involves more than just wage levels. Health Affairs (Millwood), 25, 212-218
[23] Coughlin, M.K. (2000) Recognition of staff nurse job performance and achievements: staff and manager perceptions. Association of Operating Room Nurses Journal 7, 613. Retrieved from http://www.aorn.org/AORNJournal/

[24] Khowaja K., Merchant, R.J., \& Hirani D. (2005) Registered nurses perception of work satisfaction at a tertiary care university hospital. Journal of Nursing Management, 13, 32-39

[25] Rondeau K.V., Williams E.S., \& Wagar T.H. (2009) Developing human capital: What is the impact on nurse turnover? Journal of Nursing Management, 17, 739-748

[26] Shields M.A., \& Ward M. (2001) Improving nurse retention in the National Health Service in England: The impact of job satisfaction on intentions to quit. Journal of Health Economics $20,677-70$ 